\title{
Presupposition in Courtroom Discourse
}

\author{
Dan Zhang \\ 1. College of Foreign Language, Henan University of Science and Technology, \\ Luoyang, Henan, China \\ Email:jerryzhangdan070@sina.com
}

\section{Keywords: Presupposition; Courtroom Discourse; Language strategy}

\begin{abstract}
From the analysis of the authentic data of the criminal cases, this paper is to investigate the function of the presupposition in qualitative way. The paper shows that presuppositions were used in courtroom inquiry by different participants for the purpose of investigation, confirmation and trapping. The lawyer employs the strategy of presupposition is to undermine the reliance of the testimony and try to reveal the factual situation of the case. For the defendant, he /she will try to identify the presupposition traps in order to avoid answering the presupposition question.
\end{abstract}

\section{Relevant studies on the presupposition}

Presupposition can be considered as the linguistic concept which is put forward by German scholar Gottlob Gerge. Different scholars have different views towards the definition of presupposition. Just as Keenan(1981) has stated that pragmatic presupposition is the relation between a speaker and the appropriateness of a sentence in a context. It can be defined as "a sincerity condition on the utterance by a speaker of a sentence in a context". For Levinson (2001), it can be regarded as the result of complex interactions between semantics and pragmatics, and to model such interactions we need to know considerably more about both the structure of semantic representations and the pragmatic principles that interact them. For Chinese scholar, He Ziran (1997) had defined as the prerequisite which is based on the linguistic structure and relies on the logic concept, semantic meaning and context to infer the meaning of the utterance. Scholars, both at home and abroad, think that the presupposition should from semantic and pragmatic approach to investigate. The study of linguistic study of presupposition starts in the study of semantic relation. From the semantic approach, it inherits the philosophical and logical considerations on the relationship between sentences and propositions. It can be proposed that presupposition should be represented as the semantic relation between sentences and propositions and should take the truth-value into consideration. Moreover, Truth conditional theory has been mentioned in the work of Gazdar (1979), Leech (1981), Van der Sandt(1998) and Green(1989). In comparison with semantic, Stalnaker (1974) proposed that presupposition should be studied from the pragmatic approach. Deirdre Wilson (1975) has put forward that presupposition analysis should be seen as the approach to the theory of preferred interpretations. Levinson(1983) had made a great contribution to the presupposition from the past to the present and comments on every main theory and makes comparisons and justifications of them. For Chinese scholar, Xu Jun(1996)、Zhou Liquan(2000)has proposed that presupposition should be viewed from pragmatic approach. He Ziran(2002) has stated that it is the common knowledge that addresser and addressee know before communication. Xun Shengheng(2005) and Jiang Wangqi(2003) has made deep researches about pragmatic presupposition. In addition to, some scholars have investigated from the courtroom interaction. It is found that, although the presupposition studies in legal context get off to an early start in foreign countries, little literature has been devoted to this issue in detail. Woodbury (1984) has stated that presupposition can be regarded as the relation between the speaker's intention and the choice of strategies while conducting a trial inquiry. 


\section{Presupposition in Courtroom Discourse}

Presupposition for investigation. To investigate the case that happened in the past plays the very important role of presuppositions in the court. Because the aim is to investigate much relevant information of the case in order to verify the defendant' innocent.

Eg 1:

Counsel: Would you please to tell us who has proposed to set fire of the house?

Defendant: Mark.

Counsel: David, would you please to describe the clothes you wear at that night?

Defendant: Black sweater.

Counsel: when and where you set fire?

Defendant: We set fire at Mary' house at about 8 o'clock.

From this case, it is obviously that the presupposition trigger is very important. The counsel is to designate that question. To ask this question in the first inquiry round, the counsel wants to acquire more information related with the case and confirm who has proposed to set fire. In the second inquiry round, the counsel wants to get the detailed information of the defendant, because it is a good way to verify the provided testimony. In the last inquiry round, the counsel tries to investigate the time and the place. Therefore, the presupposition that the suspect and Mark set a fire at Mary's house is embedded in the temporal phrase. Moreover, presupposition is the very effective and good strategy for the counsel to investigate more relevant information related with the case.

Presupposition for confirmation. To confirm the information that the defendant provide is very important in the courtroom inquiry. From the presuppostional questions, relevant information and reliance of testimony are confirmed and verified.

Eg 2:

Lawyer: Mary, how to remit the money to David's account?

Defendant: I don't know.

Lawyer: when and where? Who has provided the account number?

Defendant: I can't remit the money, I can't do this.

It is a crime of bribery. From this case, the lawyer asked this question to elicit from the defendant if he had any direct relations with the sum of money. There is a hidden presupposition in the lawyer's question: the defendant is the person who remitted money to David. Then we will doubt how the defendant understands the lawyer's real intention and purpose. It has involved how the presupposition is processed in the development of discourse. The potential presupposition remains a hypothesis unless confirmed by the defendant. In the process of courtroom interaction, based on the shared knowledge, both parties have changed the cognitive environment. Three kinds of cognitive effects have been yielded. From this example, the defendant is aware that the new information he received is the contradiction of his existing cognitive environment. Moreover, after the conduction of the logical inferences, the defendant realized that the lawyer's question is a kind of misleading question. Therefore, the defendant uses the vague language to answer the lawyer's question. It is a kind of way to transform the potential presupposition into the actual presupposition and try to prevent the presupposition trap. To sum up, it is evident that the presupposition is changeable in the special cognitive environment. The defeasibility of pragmatic presupposition is the result of the continuous interaction between ostension on the part of the addresser and inference on the part of the addressee, to the effect that it is due to the modification of the communicator' cognitive environment.

Presuppositions for trapping. In the courtroom discourse, some presupposition area traps. If the defendant cannot be attentively, they will be fall into the traps.

$\operatorname{Eg} 3$ :

Counsel: Can you tell us what color is Stuart' car?

Witness: May be black.

Counsel: I beg your pardon.

Witness: Er, I can't remember.

Counsel: You told the lie. At that time, Stuart is in Australia. In this case, it is obviously that the testimony that the witness provide is vital to the judgment of the court. In order to verify whether 
the testimony is real or not, the counsel on purpose use the irrelevant information embedded in his question. "What color is Stuart "car", from this inquiry, the counsel wants to acquire useful information related with the case. But the witness's answer cannot be satisfied to the counsel and he can't know the color of the car on the spot. From this inquiry round, the witness uses the vague language "Maybe black", "Er, I can't remember" to show uncertain to the color of the car. Moreover, the counsel is sure that his testimony isn't real and discredited. To sum up, it is evident that the counsel question is the presupposition trap, the defendant realized that his answer is very important, so he decided to use the uncertain words to show his nervous and the discredibility of the testimony. Therefore, in this case, it is obviously that the presupposition will be embedded to initiate the topic in order to extract relevant information. Once the topic is provided, the counsel will control the direction of the topic and hope to get the expected answer.

Eg 4:

Counsel: Miss Beth, how much money did you have in your bag?

Defendant: Um $\cdots$ about forty pounds, I think.

Counsel: That's not very much. This is an expensive country, you know. How much can you buy $\cdots$ with your forty pounds.

Defendant: To be frank, I live the cheap life.

Counsel: Did you need more money? Indeed, to have more money is to sell that heroin. It's the best way for you to become rich, is that right?

Defendant: No! It's not true.

From the above-mentioned case, it is seemed that the lawyer ask the question to convey his informative intention, that is "how much money in your bag". All the relevant information will be embedded in the question. From this question, the counsel hopes to acquire more relevant information of the case. In the second inquiry round, the counsel makes everyone in court know more information of this case. Beth has carried the heroin and wants to earn much more money. The background knowledge refers that taking heroine is the way for most people to earn much more money and it's the easy and quick way to get money. On the basis of the context, the counsel presupposes that Beth accused want to sell heroin for money. For Beth, she is to begin to infer his communicative intention and provides the uncertain answer. Therefore, in the third inquiry round, the counsel asks the question: "how much can you buy '.with your forty pounds". It is the implied meaning that forty pounds is not enough money for Beth to buy everything. On the basis of his ostension, Beth infers his communicative intention. It is obvious that their cognitive environment has been mutually manifested. Beth has realized that her answer cannot make judge and the jury believable. Therefore, she gets nervous and answers the relevant questions in an improper way.

Eg 5:

Counsel: Do you have a happy family?

Defendant: Of course.

Counsel: But why you kill your husband.

Defendant: He had deserved it. He is a devil.

Counsel: To be more specific.

Defendant: He beats me violently and asks me to buy "drugs" for him.

From the case, it has been found that in the first inquiry round, the counsel wants to convey the information, that is, the surroundings that the defendant lives in. It can give the hint to the judge and the jury that the defendant's life is very hard and his fate is very poor. Therefore, in the second inquiry round, the counsel has set the presupposition question related with case "why you kill your husband", it is the best way for the defendant to prove her bad fate and unhappy marriage. She gives us the brief introduction of his husband "deserve; devil". From this description, we can get the idea that the defendant is unwilling to kill her husband, what she should do is not her willing. In the third inquiry round, the counsel wants to get more specific information, so he/she mentions that "to be more specific", from which judge and the jury will make deep understanding about the case and can judge the case more justice. 


\section{Conclusion}

From the analysis of the courtroom discourse, it has been found that presupposition used in the judicial process for the purposes of investigation, confirmation and trapping. The function of the presupposition is a good way to facilitate the proceedings of the trial and check the credibility of the answers so that different participants can achieve his/her real intentions. Moreover, the lawyer employs the strategy of presupposition is to undermine the reliance of the testimony and try to reveal the factual situation of the case. For the defendant, he /she will try to identify the presupposition traps in order to avoid answering the presupposition questions.

\section{Acknowledgement}

This research was financially supported by Technology Department of Henan Province in 2012 (Grant NO. 132400410700) and key planning projects of philosophy and social science of Luoyang in 2014(Grant NO. 2014A028).

\section{References}

[1] D.Brenda. Language in the legal process. Law \& Society Review, Vol.3 (1980) No.3,p31.

[2] J.M.Conley\& W.M.O'Barr. Just words: Law, Language and power. Chicago: University of Chicago Press. 1980.

[3] R.M.Kempson. Semantic Theory. Cambridge: Cambridge University Press.1977.

[4] P.Liu. On Pragmatic Presupposition Based on Courtroom Interactions.(MS. Northwest Normal University, China, 2011).p6-10.

[5] L.Liu. Presupposition in Courtroom Questioning: An Adaptation-Relevance Model.(MS. Southwest University, China,2009).p15-20.

[6] Q.T.Yuan. The Realization of Lawyer's Language Power in Cross-examination a Pragmatic Approach. (MS. Southwest University of Political Science \& Law, China, 2012).p28-45.

[7] W.W.Shi. Study on the Presupposition in Courtroom Inquiry. (MS. Shang Dong University, China, 2009).p.25.

[8] M.X.Xiao. Impoliteness Discourse in Courtroom.(MS, Hunan University of Science and Technology, China 2008),p39-49.

[9] D. Bousfield. Impoliteness in interaction. New York: John Benjamins publishing company, 2008.

[10] P. Brown \& S. Levinson. Politeness: Some Universals in Language Usage. Cambridge: Cambridge University Press, 1987. 